\title{
Household water use and conservation models using Monte Carlo techniques
}

\author{
R. Cahill ${ }^{1}$, J. R. Lund ${ }^{2}$, B. DeOreo ${ }^{3}$, and J. Medellín-Azuara ${ }^{2}$ \\ ${ }^{1}$ United States Army Corps of Engineers, Portland, Oregon, USA \\ ${ }^{2}$ Center for Watershed Sciences, University of California, Davis, Davis, California, USA \\ ${ }^{3}$ Aquacraft Inc., Boulder, Colorado, USA \\ Correspondence to: R. Cahill (ryan.cahill@usace.army.mil) \\ Received: 17 March 2013 - Published in Hydrol. Earth Syst. Sci. Discuss.: 17 April 2013 \\ Revised: 19 August 2013 - Accepted: 4 September 2013 - Published: 15 October 2013
}

\begin{abstract}
The increased availability of end use measurement studies allows for mechanistic and detailed approaches to estimating household water demand and conservation potential. This study simulates water use in a single-family residential neighborhood using end-water-use parameter probability distributions generated from Monte Carlo sampling. This model represents existing water use conditions in 2010 and is calibrated to 2006-2011 metered data. A two-stage mixed integer optimization model is then developed to estimate the least-cost combination of long- and short-term conservation actions for each household. This least-cost conservation model provides an estimate of the upper bound of reasonable conservation potential for varying pricing and rebate conditions. The models were adapted from previous work in Jordan and are applied to a neighborhood in San Ramon, California in the eastern San Francisco Bay Area. The existing conditions model produces seasonal use results very close to the metered data. The least-cost conservation model suggests clothes washer rebates are among most cost-effective rebate programs for indoor uses. Retrofit of faucets and toilets is also cost-effective and holds the highest potential for water savings from indoor uses. This mechanistic modeling approach can improve understanding of water demand and estimate cost-effectiveness of water conservation programs.
\end{abstract}

\section{Introduction}

Models predicting residential water use and conservation potential based on empirically estimated parameters, waterconsuming device turnover rates, and regression analysis are fairly common. The uses and drawbacks of various types of these models are detailed and then contrasted with the model developed here.

Some water utilities develop regression relations for total single-family residential water use based on historical trends for planning purposes (Sacramento Department of Utilities, 2011; San Jose Environmental Services Department, 2011). Such models assume increasing levels of conservation in the future, but often give little indication of where this conservation will come from. Estimating realistic conservation potential for each end use under various drought, pricing, and demographic conditions requires an understanding of where water is currently being used in homes. Measurement-based studies now provide reliable data on water consumption for each end use (e.g. toilets, showers, irrigation) (Mayer and DeOreo, 1999), yet these studies can be costly.

Using end use data, some models estimate conservation potential by assuming natural replacement rates of appliances with more efficient appliances and calculating the expected amount of water saved (CALFED Bay Delta Program, 2006; Blokker et al., 2010; Gleick et al., 2003). These models often assume average savings values for retrofitting devices and apply them uniformly to the proportion of the population expected to adopt the devices. Such a modeling approach is useful for long-term, large-scale predictions of conservation potential, but does not allow for much heterogeneity of behavior or population characteristics.

Case studies for Europe, Africa, America and Australia (Blokker et al., 2010; Gumbo et al., 2003; Kampragou et al., 2011; Sauri, 2003), highlight the use of modeling to assess the effectiveness of water conservation programs. 
Kampragou et al. (2011) summarize guiding principles of water demand management strategies and programs, presenting case studies for Canada, the US, Europe and Asia that employ both market and non-market incentives. The effectiveness of economically driven strategies seems to be linked to the prevailing socioeconomic conditions (Kampragou et al., 2011). Sauri (2003) presents a qualitative approach to water demand with historical information on water use and urban development patterns that discusses the role of pricing, water sources augmentation, technology, and consumer outreach for the Metropolitan Region of Barcelona in Spain. Jacobs and Haarhoff (2004) present a model that predicts end uses by household, using detailed physical and behavioral parameters affecting demand.

Some models rely heavily on large amounts of data to model end use and conservation potential. Blokker et al. (2010) present a simulation model for water demand patterns in a region of the Netherlands using a very small timescale at the residential level. This method is presented as an alternative to metering, using data management programs that have proved to be useful in other areas (Gumbo et al., 2003). The end-use model developed by Blokker estimates water demand based on parameters affecting water use (e.g. frequency of hand washing). Compared to household metered data, the model had good fit overall. The end-use model includes pulse intensity, time of use, and duration for each end-use type, user, and busy time per end use. However, this model does not include outdoor uses (which are small in the Netherlands) and, whereas aggregate demand is close to the measured data, the approach relies on high quality appliance information and behavioral data, which is more suitable for regions with homogeneous demographics (Sauri, 2003).

Still other household use models attempt to calculate the water used for each end use of individual homes using regression analysis (DeOreo et al., 2011). These models build heavily on end use measurement data paired with survey responses, and find statistically significant parameters affecting each end use of water. Empirical equations are then developed to predict each end use as a function of these significant parameters. The strength of the regression analysis results for estimating water demand of individual homes is often low, with coefficients of determination $\left(R^{2}\right)$ typically around 0.4 (DeOreo, 2011). Such models perform reasonably for estimating current average water use for groups of households, and are useful in estimating the effectiveness of and potential for water conservation measures under different scenarios. Water pricing or more complex rationing conditions are usually absent from these models. However, literature on household water demand often concludes that price is an important factor affecting total water use (Dalhuisen et al., 2003; Rosenberg, 2010).

While regression-based (inductive) models are useful for different purposes, a more mechanistic or deductive modeling approach can now be undertaken with the large amounts of data available from end use measurement studies. In contrast to more inductive or empirical techniques for household water demand analyses, this paper presents a more deductive ("causal") household end-use model based on physical parameters affecting water use that vary by household. We employ a Monte Carlo approach to include variability in household physical characteristics and behavior when estimating distributions of household water use and conservation potential. This modeling approach is applied to a neighborhood in the East Bay Municipal Utility District (EBMUD) service area, California. The model extends a previously developed model that estimated household water use in Amman, Jordan (Rosenberg et al., 2007). Rosenberg's model accurately reflected actual water use patterns in Jordan, but such an approach has not been attempted in the US, where urban water utilities often offer water conservation rebates to their customers.

After an overview of the modeling approach, a short summary of the case study area (San Ramon, California) is presented. Then, (1) existing conditions use, and (2) least-cost conservation models are described in detail. Third, calibration and modeling results are presented and discussed, with a cost-effective assessment of different short- and long-term conservation actions. Finally, the inherent limitations and desirable extensions of this modeling approach are discussed.

\section{Modeling overview}

The framework developed for this study can be thought of as two interrelated models: (1) "existing conditions" and (2) "least-cost conservation" (Fig. 1). The "existing conditions" component simulates water demand by end use for a neighborhood, and can be calibrated to metered data. The parameterized demand equations from the "existing conditions" component are later employed by the "least-cost conservation" model to estimate the cost minimizing short- and longterm water saving actions for each household. To make the distinction between each model clearer, Table 1 presents a list of possible outputs desired by utilities along with the model that can provide the output. The list in Table 1 is not comprehensive, but it shows capabilities of each model.

\section{1 "Existing conditions" water use model}

The existing conditions model estimates household water use by end use using uncertain physical parameters, calibrated to metered data. This model is analogous to the models developed by Blokker et al. (2010) and Jacobs and Haarhoff (2004). In this model, conservation devices such as low flow showerheads are present in their assumed market penetration rates, and the households make no behavioral changes. This simulation approach allows evaluation of specific alternatives' effect on total water use (e.g. What would the water use be if all households installed warm-season turf?). The basic process is as follows. 
Table 1. Example capabilities of existing conditions and least-cost conservation models.

\begin{tabular}{lcc}
\hline Result desired by utility & $\begin{array}{c}\text { Existing } \\
\text { Conditions }\end{array}$ & $\begin{array}{c}\text { Least-Cost } \\
\text { Conservation }\end{array}$ \\
\hline Water use by end use in 2010 & $\mathrm{x}$ & \\
\hline $\begin{array}{l}\text { Expected water use after price } \\
\text { increase of } 10 \%\end{array}$ & $\mathrm{x}$ \\
\hline $\begin{array}{l}\text { Savings after penetration of } \\
\text { HET increases to 40\% }\end{array}$ & $\mathrm{x}$ & \\
\hline $\begin{array}{l}\text { Cost-effectiveness of payment } \\
\text { for less-grass area (Cash for grass) }\end{array}$ & & $\mathrm{x}$ \\
\hline $\begin{array}{l}\text { Budget for showerhead } \\
\text { replacement rebate program }\end{array}$ & $\mathrm{x}$ \\
\hline $\begin{array}{l}\text { Water consumption of proposed } \\
\text { new subdivision }\end{array}$ & $\mathrm{x}$ & $\mathrm{x}$ \\
\hline $\begin{array}{l}\text { Outdoor water consumption } \\
\text { with climate change }\end{array}$ & \\
\hline $\begin{array}{l}\text { Water use with water rationing } \\
\text { policy }\end{array}$ & \\
\hline
\end{tabular}

1. Develop parameter probability distributions.

2. Sample distributions to create a "house".

3. Calculate water use from sampled parameters.

4. Repeat steps 2 and 3 for 500 households (Monte Carlo iterations).

5. Calibrate results to metered data.

\section{2 "Least-cost conservation" model}

The least-cost conservation component incorporates household behavior into the existing conditions component. The household use and sampled parameters for each Monte Carlo "house" from the existing conditions model are used as starting points (or initial conditions) for the least-cost conservation model. In the least-cost model, each household has several available long-term and short-term conservation actions. Long-term actions apply for all future conditions, while short-term actions apply to individual water shortage events. Each conservation action has an associated cost and effectiveness in reducing water use dependent on the sampled parameters of the house (e.g. a house with a larger number of occupants that chooses to replace toilets will save more water). For each household, a combination of these long-term and short-term conservation decisions exists that will minimize cost; the least-cost conservation model finds this mix of actions. This two-stage (long-term and shortterm) optimization approach has been used by Lund (1995) and Garcia-Alcubilla and Lund (2006). As a stochastic optimization model with recourse decisions, the model may not

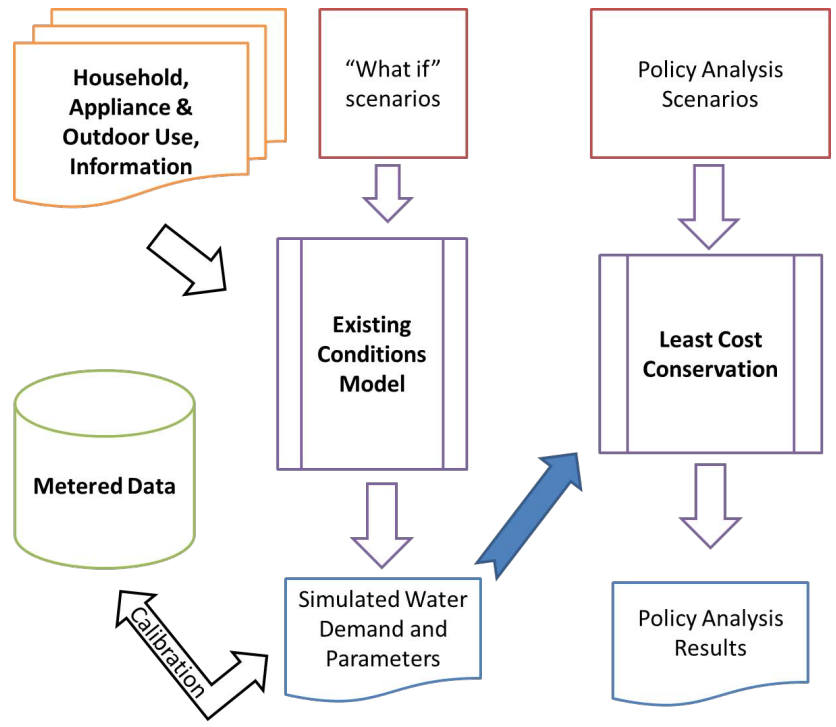

Fig. 1. Modeling framework for economic analysis of water conservation.

actually predict what real homeowners will do. The model assumes cost-minimizing, rational behavior of all homeowners, assuming they have perfect knowledge of the probabilities of future shortages and corresponding price increases. However, the model results do provide a likely upper bound (from an economic perspective) of the conservation potential for the neighborhood. The changes in household water use resulting from policy changes (e.g. differing rebate strategies or pricing schemes) can be evaluated in the least-cost conservation component. The least-cost component is a helpful complement to the existing conditions model: while the existing conditions model calculates end uses, the least-cost conservation model shows which end uses households find most cost-effective to reduce. The basic process is as follows.

1. Define conservation actions and effectivenesses (how much water is saved).

2. Define event probabilities and corresponding water bill increases.

3. Define costs of actions.

4. Define and solve the optimization equations using mixed integer linear programming.

Steps 1-4 are performed separately for each of the households previously generated in the existing conditions model.

\section{Metered data}

EBMUD provided metered data for 151 households from 2006-2011 in a neighborhood in San Ramon, CA, which 
were employed to calibrate the model. San Ramon is east of the Oakland Hills, where there is less precipitation, warmer temperatures, and more sunny days than areas west of the hills. Therefore, the metered homes should have more outdoor water use than the average EBMUD household. Furthermore, the houses are in an affluent neighborhood near a golf course, where the median selling price of homes was approximately $\$ 900000$ as of 2011 (Zillow, 2011). The "standard new homes" end use study (DeOreo, 2011) is particularly applicable to this neighborhood for obtaining parameter distributions on appliances and water use, because both the homes in the neighborhood and in the study were built around 2000 .

\section{Existing conditions water use model}

The basic modeling process for the existing conditions model is described in Sect. 2.1; now, the details of the model are presented.

\subsection{Parameter probability distributions}

Many parameters affect household water use (e.g. type of toilets, household size, lot size, etc.). Instead of assuming average numbers for each parameter, probability distributions are used to capture variability in water use parameters. In the model, 69 parameters are used to define the water use of each house. The distributions of these parameters were taken from end use studies mentioned earlier or other literature, when available; otherwise, engineering estimates were used. A full list of the parameters and their distributions is presented in Cahill (2011).

\subsection{Distribution sampling}

After the distributions have been developed, each Monte Carlo iteration randomly samples these distributions independently to create a modeled "house". Each sampled "house" does not line up with a physical house, but the whole sample of houses should approximate the neighborhood's water use. Covariance between parameters was not included in the sampling process, although such relations do exist (DeOreo et al., 2011). Water use estimates could be unrealistic for some households due to this assumption of parameter independence. For example, shower length and shower frequency may be inversely related, but the model does not account for this, so there may be some households that take long showers very often. This assumption of parameter independence could be removed as a future improvement to this model.

\subsection{Calculation of water use from parameters}

After the parameters have been randomly sampled for a household, relations between the parameters are used to estimate the water demand by end use. For example, water used for laundry can be estimated using Eq. (1):

$$
Q=\left(\frac{\text { liters }}{\text { cycle }}\right)\left(\frac{\text { cycles }}{\text { week } \cdot \text { person }}\right)\left(\frac{\text { persons }}{\text { house }}\right)\left[\frac{1 \text { week }}{7 \text { days }}\right] \text {. }
$$

Each factor in the equation is randomly sampled for each household (except physical constants). Equations have been developed for each end use, and the full list of relations can be found in Cahill (2011). For each end use and household, water use is calculated within the Monte Carlo loop. The model used two seasons (wet winter and dry summer) to further disaggregate the water use, as precipitation and evapotranspiration values are quite different in the dry and wet seasons and affect outdoor use (CIMIS, 2011).

\subsection{Calibration to metered data}

The results from the existing conditions model are compared to metered data to ensure that reasonable ranges of results are being produced. Only one parameter was set to match the metered data - the percent of landscaped area that is lawn. It was set to a value of $65 \%$, which is close to the average lawn proportion of landscape in the study area (EBMUD, 2002). This calibration was done manually by trial and error, although a more sophisticated approach could have been taken to match the data more closely. This paper focuses on new modeling methods, rather than rigorous calibration, so a simple calibration scheme is sufficient for the purposes of this paper.

Goodness of fit of the existing conditions model to the metered data was formally tested using the KolmogorovSmirnov 2 variable test (Smirnov, 1948), resulting in a $p$ value of 0.36 , which fails to reject the null hypothesis that modeled results and metered data have the same underlying distribution. This is also illustrated in Fig. 2.

A summary of the modeled results for each end use is compared to the findings from other end use studies in Fig. 3. The existing conditions simulated water use fits well with the standard new homes data set with the exception of outdoor water use in winter. This is not surprising, since these metered houses are located near a golf course with a drier climate than the standard new homes data set.

\section{5 "Least-cost conservation" model}

The basic modeling process for the least-cost conservation component described in Sect. 2.1 and its relation to the existing conditions component is given in Fig. 1. The details of the model inputs and the optimization formulation are presented below. 


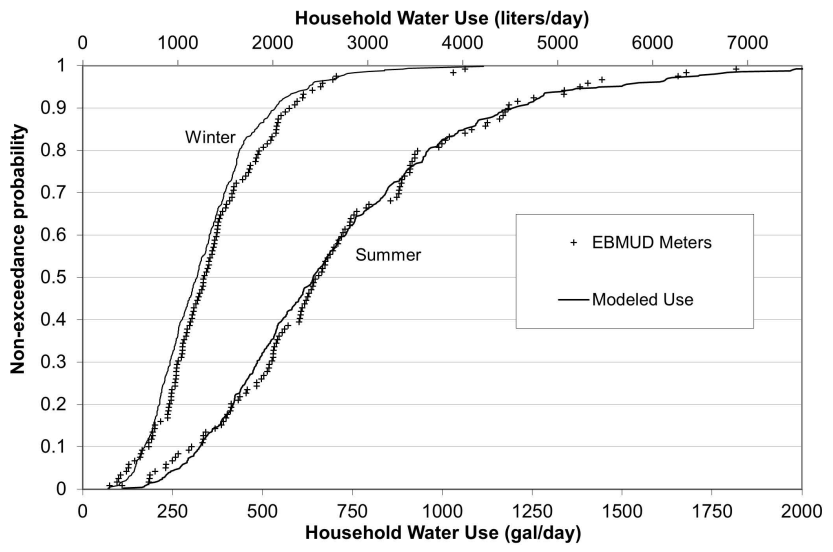

Fig. 2. Calibration of existing conditions modeled use to metered seasonal use.

\subsection{Model inputs}

\subsubsection{Conservation actions and effectiveness}

A list of the short-term and long-term conservation actions and the end use available to households appears in Table 2. Short-term actions may or may not be activated during each event, while long-term actions apply to all events. Both shortterm and long-term actions are expected to decrease water use.

Each conservation action saves a given amount of water (effectiveness), depending on the initial state of the household. For example, the relationship estimating the amount of water saved on a daily basis by installing a water-conserving laundry machine is shown in Eq. (2) below:

$$
\begin{aligned}
Q_{\mathrm{s}}= & \left(\left(\frac{\text { liters }}{\text { cycle }} \text { Std. }\right)-\left(\frac{\text { liters }}{\text { cycle }} \text { Efficient }\right)\right) \\
& \cdot\left(\frac{\text { cycles }}{\text { week } \cdot \text { person }}\right)\left(\frac{\text { persons }}{\text { house }}\right)\left[\frac{1 \text { week }}{7 \text { days }}\right] .
\end{aligned}
$$

From Eq. (2), households that already have a water efficient laundry machine will have an effectiveness value of zero for $Q_{\mathrm{s}}$. Since each house in the Monte Carlo iterations has a different value for each randomly sampled parameter in the Eq. (2), the amount of water saved by replacing a laundry machine will vary by household. The full set of equations can be found in Cahill (2011).

\subsubsection{Water shortage event descriptions}

Six different water shortage events are considered in the least-cost model - three events in the winter and the same three corresponding events in the summer to account for seasonality in water supply. These events were based on the EBMUD water shortage contingency plan and are presented in Table 3 (EBMUD, 2011).

In this study, water shortage events are characterized by the price paid for water by the homeowners. In other words,

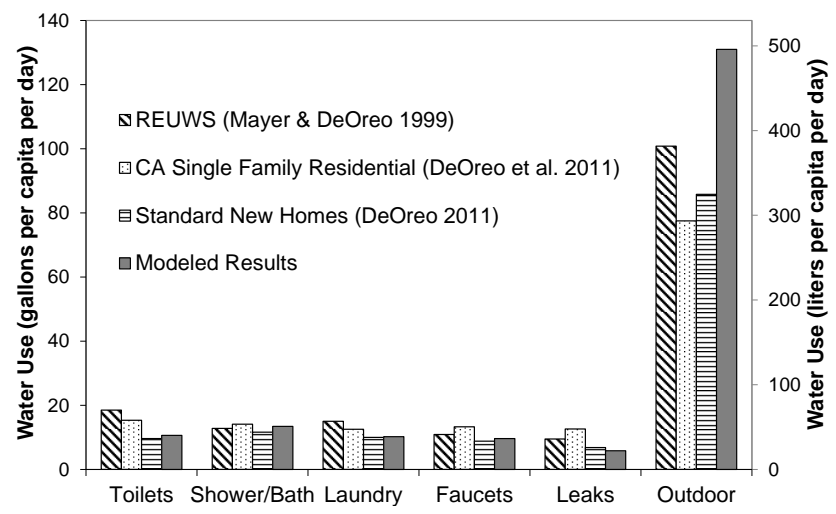

Fig. 3. Average annual modeled end uses of water compared to end use studies.

a household may use as much water as desired during a shortage event, but the price paid for water use will be higher.

\subsubsection{Costs}

In any optimization model, the costs (penalties) of actions are the main driver of the results. Three components comprise the total cost to a household: the water bill, the cost of longterm actions, and the cost of short-term actions. Costs are summarized in Cahill (2011).

The water rates used in this model (typically USD $0.002 \mathrm{~L}^{-1}$; hereafter USD indicated as \$) were based on the 2010 increasing block rate schedule, and include both water and wastewater charges, more accurately reflecting the total cost to the homeowner (EBMUD, 2010). Various surcharges can be incurred by households during drought events and are included in the model (EBMUD, 2011).

\subsubsection{Long-term actions}

All long-term conservation actions include installing some sort of new water-saving fixture (as opposed to behavioral change). Since the devices have a limited lifespan, design lives were used to annualize the costs, assuming a discount rate of $6 \%$. Since each device in the house is modeled, the number of devices needing replacement is considered in the cost. For example, a house may have 3 toilets, one of which is high efficiency toilet (HET), one of which is ultra low flush toilet (ULFT), and one of which is "standard". The model recognizes that 2 toilets must be replaced if all toilets are to become HET, and adjusts the cost accordingly. Alternatively, each toilet could be considered as a separate decision variable.

The costs in the model reflect both capital and installation costs. Not all homeowners are assumed to be equally capable of installing devices, so only a proportion of households were assumed able to independently install each type of device. Each house was assigned a random "handiness factor" 
Table 2. Actions available to households in the least-cost conservation model.

\begin{tabular}{lll}
\hline End Use Affected & Long-term Actions & Short-term Actions \\
\hline Shower & Retrofit showerheads & $\begin{array}{l}\text { Reduce shower length } \\
\text { Reduce shower-taking frequency }\end{array}$ \\
\hline Toilet & $\begin{array}{l}\text { Retrofit all standard toilets with HETs } \\
\text { Retrofit all standard toilets with ULFTs } \\
\text { Retrofit all ULFTs with HETs }\end{array}$ & Flush only when necessary \\
\hline Faucet & Retrofit bathroom faucets & Turn off faucets while washing \\
\hline Laundry & Install conserving laundry machine & Reduce laundry-washing frequency \\
\hline Leaks & & Find and fix leaks \\
\hline Lawn & Install xeriscape & Stress irrigate \\
& Install warm-season turf & \\
\hline Garden/Landscape & Install xeriscape & Stress irrigate \\
& Install drip irrigation system & \\
\hline Car Wash & Install smart irrigation controller & Wash car with buckets \\
\hline Pool & & Wash car at gas station \\
\hline
\end{tabular}

between 0 and 1; if the household's handiness factor exceeds the cutoff proportion for a given action, the household must use professional installation. Households with handiness factors below the cutoff have the option of installing the device themselves or having it professionally installed, whichever has the lower cost. Some tasks such as changing out showerheads can be done by most people, while more difficult tasks like installing xeriscapes have more restrictive handiness cutoffs.

\subsubsection{Short-term actions}

The financial costs of nearly all short-term actions are zero, as they are behavioral changes rather than retrofits. There is no concept of a "handiness" factor for the short-term actions, as it is assumed that everyone can carry out these actions. If hassle costs are omitted, nearly all short-term actions are implemented in every event because they save water and cost nothing to the household.

Hassle costs are additions to financial costs that reflect inconvenience costs to households beyond purely financial costs of conservation actions. Often, households do not reduce consumption due to the hassle costs of conservation (Dolinicar and Hurlimann, 2010). Unfortunately, little has been written on estimating hassle costs of conservation activities. Contingent valuation studies are the preferred method of estimating hassle costs, but such studies do not exist for the water conservation activities considered in the model. In the absence of contingent valuation studies, economic literature relating to opportunity costs is the most appropriate.
When hassle costs are included, the conservation actions are assumed to take a given amount of time, which can then be translated into a dollar amount based on the value of time to a particular household (Narasimhan, 1984). To introduce uncertainty, the annual household income was converted to an hourly amount and used as the value of time for a household. Such an approach reflects a higher opportunity cost of time for higher-income earners, a common assumption in economics literature (Anderson and Song, 2004; Narasimhan, 1984). These assumed hassle costs produce more realistic behavior than assuming no hassle costs.

\subsection{Least-cost conservation model formulation}

A two-stage mixed-integer linear program was used to formulate the optimization problem. The first stage consists of long-term actions and costs, and the second stage includes actions and costs for each short-term shortage event. For a complete description of all inputs to the optimization model see Cahill (2011).

\subsubsection{Decision variables}

The decision variables are listed below.

- $S_{s, e}$ : short-term actions, a binary variable defined over the set $s$ of short-term actions (third column in Table 2), and for the set $e$ of all six water shortage events. 
Table 3. Description of water shortage events.

\begin{tabular}{|c|c|c|c|c|c|c|}
\hline Event & Description & Probability & $\begin{array}{l}\text { Volumetric } \\
\text { use price } \\
\text { increase } \\
(\%)\end{array}$ & $\begin{array}{l}\text { Freeport } \\
\text { source } \\
\text { surcharge } \\
\text { (14\% increase) }\end{array}$ & $\begin{array}{l}\text { Ration } \\
\text { amount (\% } \\
\text { reduction in } \\
\text { original use) }\end{array}$ & $\begin{array}{l}\text { Penalty for } \\
\text { exceeding } \\
\text { rationed } \\
\text { amount } \\
\left(\$ / 2.83 \mathrm{~m}^{3}\right)\end{array}$ \\
\hline \multicolumn{7}{|c|}{ Summer } \\
\hline 1 & Regular delivery & 0.35 & $0 \%$ & no & $0 \%$ & $\$ 0$ \\
\hline 2 & Shortage & 0.1 & $10 \%$ & no & $20 \%$ & $\$ 2$ \\
\hline 3 & Severe Shortage & 0.05 & $10 \%$ & yes & $30 \%$ & $\$ 2$ \\
\hline \multicolumn{7}{|l|}{ Winter } \\
\hline 1 & Regular delivery & 0.35 & $0 \%$ & no & $0 \%$ & $\$ 0$ \\
\hline 2 & Shortage & 0.1 & $10 \%$ & no & $20 \%$ & $\$ 2$ \\
\hline 3 & Severe Shortage & 0.05 & $10 \%$ & yes & $30 \%$ & $\$ 2$ \\
\hline
\end{tabular}

- $L_{l}$ : long-term actions, a binary variable defined over the set $l$ of long-term actions (second column in in Table 2).

- $B_{e}$ : water bill (\$/billing period) for each water shortage event $e$.

- $U_{e}$ : water use (liters/day) for each water shortage event $e$.

- $E_{u, e}$ : end use saved (liters/day) for each end use $u$ and each water shortage event $e$.

- $W_{e}$ : water saved (liters/day), for each water shortage event $e$.

Decision variables for the water bill, water use, etc., are not really "decisions" that the household has direct control over, but they are defined as decision variables to incorporate complexities, such as piecewise-linear representation of water bills and interactions between conservation actions.

\subsubsection{Objective function}

The objective function (Eq. 3) is to minimize the total expected economic cost of all water conservation decisions, including permanent conservation $L_{l}$, short-term conservation decisions for each shortage event $S_{s, e}$, and the household water bill for each shortage event $B_{e}$ :

$\operatorname{Minimize} Z=\sum_{l} c_{l} L_{l}+j \sum_{e}\left[p_{e}\left(i \sum_{s}\left(c_{s} S_{s, e}\right)+B_{e}\right)\right]$

where: $c_{l}$ represents the annualized long-term action costs (\$/year); $c_{s}$ represents the short-term action costs (\$/day); $p_{e}$ is probability of event $e ; i$ is the number of events per billing period (60 days/billing period) and $j$ is the number billing periods per year (6 billing periods/year).

\subsubsection{Constraints}

A summary of the constraints to the model is given below (non-negativity applies for all decision variables):

1. Maximum effectiveness: the water saved cannot exceed the initial water use (inequality 4) or the sum of the water conserved in each end use category (inequality $5)$.

$W_{e} \leq O_{e}, \quad \forall e$,

$W_{e} \leq \sum_{u} E_{u, e} \quad \forall e$,

where: $O_{e}$ is the original water use of the household in a water shortage event $e$ (this input comes from the results of the existing conditions component).

2. Conserved water use: the final water use is the original water use minus the amount of water saved from conservation actions (inequality 6):

$U_{e} \geq O_{e}-W_{e}, \quad \forall e$.

3. Discrete choices: no conservation action can be partially implemented (Eqs. 7, 8):

$S_{\mathrm{s}, \mathrm{e}}=0$ or $1, \quad \forall s, e$,

$L_{l}=0$ or $1, \quad \forall l$.

4. Mutually exclusive actions: some actions cannot be implemented simultaneously (inequalities 9 and 10):

$\sum_{12} \mathrm{~L}_{l 2} \mathrm{LX}_{l, l 2} \leq 1, \quad \forall l$, 
$\sum_{\mathrm{s} 2} \mathrm{~S}_{s 2, e} \mathrm{SX}_{s 2, s} \leq 1, \quad \forall s, e$,

where: $\mathrm{LX}_{l, l 2}$ equals 0 or 1 for each possible combination of long-term actions and set $l 2$ is same as set $l$. A value of 1 corresponds to mutually exclusive actions (e.g. washing car with buckets or washing car at car wash). Likewise, $\mathrm{SX}_{s 2, s}$ contains all possible combinations of short-term actions with 1 for mutually exclusive long-term actions and set $s 2$ is an alias for set $s$.

5. Mutually dependent actions: some actions (inequalities 11 and 12) depend on implementation of other actions.

$\sum_{l 2} \mathrm{~L}_{l 2} \mathrm{LR}_{l, l 2}=0, \quad \forall l$,

$\sum_{s 2} \mathrm{~S}_{s 2, e} \mathrm{SX}_{s 2, s} \leq 0, \quad \forall s, e$

where: $\mathrm{LR}_{l, l 2}$ equals 0 or 1 for each possible combination of long-term actions (same as inequality 9). A value of 0 corresponds to mutually dependent actions (e.g. "install smart irrigation controller" applies to both the lawn and garden end uses). Likewise, $\mathrm{SX}_{s 2, s}$ contains all possible combinations of short-term actions (same as inequality 10) with 0 for mutually requiring short-term actions.

6. Increasing block water bills: unit water price increases with increasing use (inequality 13).

$B_{e} \geq F+i V_{1} U_{e}, \quad \forall e$,

where: $F$ is the flat water fee for billing period and $V_{n}$ the variable water fee for usage block $n$.

7. Rationing penalties: surcharges apply if a household exceeds their rationed water use (inequality 14).

$B_{e} \geq F+i\left(V_{1} R_{e}+\left(P_{e}+V_{1}\right)\left(U_{e}-R_{e}\right)\right), \quad \forall e$,

where: $R_{e}$ is the rationed water amount for water shortage event $e$ and $P_{e}$ the penalty for exceeding the rationed amount in water shortage event $e$.

8. Interactions between actions: inequality 15 shows a cap on effectiveness by end use is used to account for interactions between conservation actions (e.g. savings from reducing shower length and reducing shower frequency are not independent of each other). This constraint ensures that water savings still make physical sense when multiple actions are implemented.

$E_{u, e} \leq \mathrm{EMAX}_{u, e}, \quad \forall u \forall e$,

where: $\operatorname{EMAX}_{u, e}$ is the maximum limit of water saving for end use $u$ in event $e$

\section{Results}

Results from "base condition" runs are presented for the study neighborhood in San Ramon, followed by the results of changing indoor device rebates.

\subsection{Base condition runs}

The results from base condition runs are a benchmark for all alternative runs, showing the reasonable conservation potential beyond the existing conditions model. These runs do not have rebates for any conservation actions, and water prices are at 2010 levels. Two separate base condition runs were computed - one with financial costs only and one including hassle costs. The average household use after adopting least-cost conservation actions is $1820 \mathrm{~L}$ per household per day (Lphd) (480 gallons per household per day, gphd) with financial costs only and 1930 Lphd (510 gphd) with hassle costs, while the average household use under the existing conditions model was 2040 Lphd (540 gphd). This reduction of $12 \%$ with financial costs only (6\% with hassle costs) means it would be unrealistic to achieve conservation beyond this amount under current water price rate structures and no rebates, as more conservation would not be cost-effective for the neighborhood and each home individually. Figure 4 shows water use after least-cost conservation compared to existing conditions. Many high water users reduce consumption by large amounts, while the low water users can save less.

All future results are extracted from runs with hassle costs, as these runs are expected to be more realistic. The modeled adoption rates and ranges of effectiveness of conservation actions for the base conditions are shown in Fig. 5.

For permanent conservation actions, installing smart irrigation controllers has a $45 \%$ adoption rate. The relatively low implementation rates of most other outdoor conservation activities indicate that these conservation actions are not cost-effective for most households, but the households that implement them save large amounts of water. With current water price structures, no household finds it worthwhile to install a xeriscape or warm-season turf (not shown in Fig. 5). The indoor actions are implemented more often, but their savings are usually less than outdoor conservation.

The relative frequency of adoption of short-term conservation actions by season and drought event appear in Fig. 6. The short-term actions are adopted with highest frequency during severe shortages in the summer, which is when adopting these actions saves the most water and money. However, it is financially worthwhile for some homes to adopt shortterm actions even when there is no shortage. Stress irrigation shows the greatest seasonal variation, as the water saved by stress irrigation in the winter is much lower than in the summer. These preliminary model results also indicate where additional calibration and study seems desirable, such as for the 


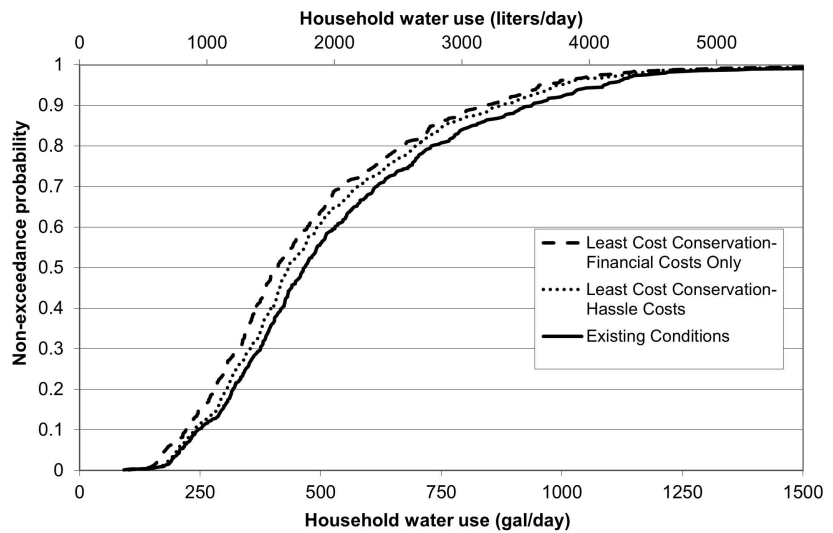

Fig. 4. CDF of water use under existing conditions and least-cost conservation.

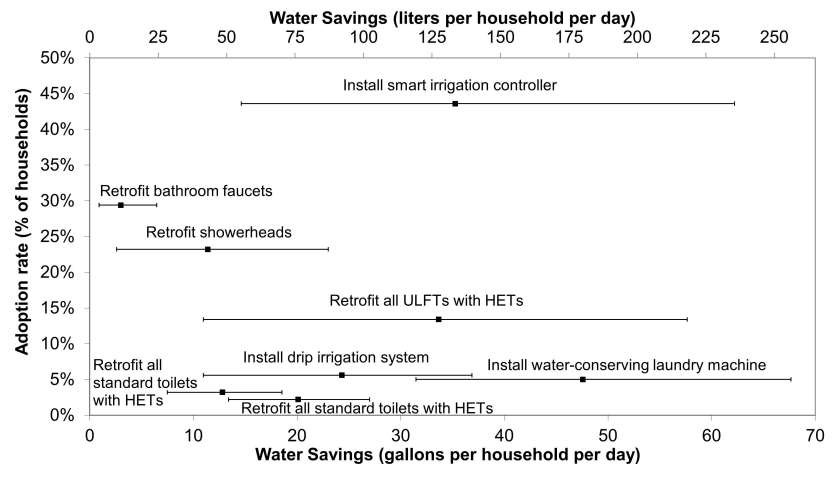

Fig. 5. Modeled market penetration and average water savings for long-term conservation actions, base conditions run with hassle costs (error bars are 10th and 90th percentiles).

seemingly high percentage of households flushing only when necessary.

\subsection{Indoor device rebates}

While the least-cost conservation model can be used in many ways, the effectiveness of indoor rebates will be focused on here as an example application for utilities. The ratio of water saved to total rebates disbursed indicates cost-effectiveness. Rebate strategies with high ratios provide the highest water savings per unit cost of conservation. Figure 7 shows this relation for varying rebate levels. These results were generated by re-running the least-cost conservation model for each distinct rebate scenario - the scenario with a rebate of $\$ 0$ is the "base condition" run. As nominal rebate levels increase, the cost-effectiveness decreases due to free riders (who would have conserved even with a lower rebate). The plot suggests that rebates for efficient clothes washers are the most costeffective, saving the most water per rebate dollar invested.

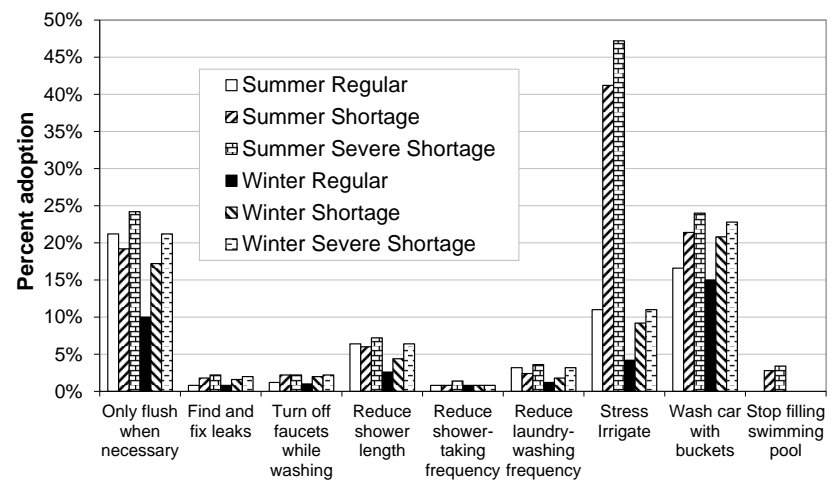

Fig. 6. Modeled average market penetration for short-term conservation actions by season and drought event, base conditions with hassle costs.

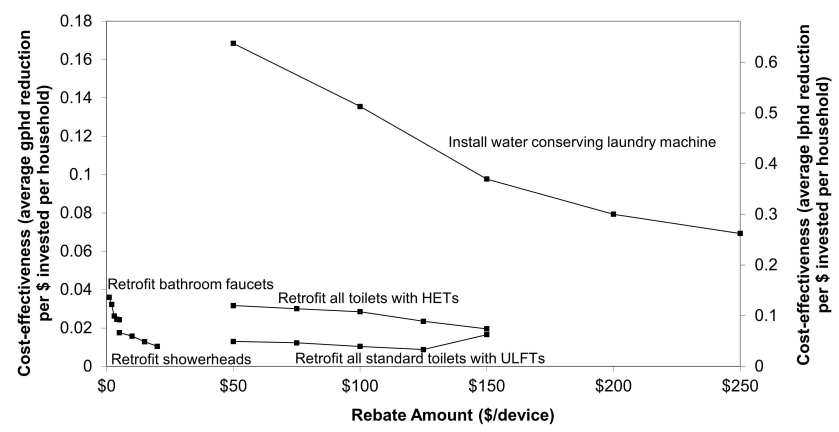

Fig. 7. Cost-effectiveness of rebate programs, average use reduction per rebate dollar invested by the utility per household.

\subsection{Limitations of the model}

While the least-cost conservation model has many capabilities, its limitations also are important.

1. Rebate aspects of the model do not account for "free riders", people who intend to replace their devices anyway and reap the benefit of a rebate without being enticed by it (Sovocool, 2005). However, such households can be identified by comparing results with and without rebates - the proportion of households that conserve when there is a rebate of $\$ 0$ are the free riders.

2. The model assumes that all households behave rationally to minimize the cost to themselves, which is not always the case. Many decisions on conservation are not affected strongly by the actual savings gained or the reduction in cost to the household (Komor and Wiggins, 1988). Calibration of hassle costs can help in this regard. Furthermore, a payback period measure would be a good addition to the model, as the life span of some appliances may exceed the planned occupancy period of some homeowners. 
3. The optimization model is built from a homeowner's perspective, so it cannot calculate the best suite of rebates from the utility's perspective directly. However, a similar model from a utility's perspective might be formulated and used (Wilchfort and Lund, 1997), and calibrated based on household model results.

4. Although the model provides a more mechanistic framework for water conservation studies, it requires estimation of many parameters. Much of this information is now available from recent end use studies. Outdoor water use data remains the greatest uncertainty.

5. While household water conservation reduces water costs at the household level, this also reduces revenues for the utility that depend on the proportion of households employing conservation measures. Some pricing mechanisms are needed to cover operation costs of the utility, however, quantification of these are beyond the scope of this paper.

\section{Conclusions}

The approach taken here produces reasonable existing conditions water use estimates and provides insights on household conservation potential for the metered homes in a San Ramon, California, neighborhood. The modeled results were comparable to measurements from other end use studies and were calibrated with little difficulty to the metered data.

The least-cost conservation model can provide useful insights. Indoor conservation is more widespread, but the savings are lower than outdoor conservation. The most cost-effective widely adopted indoor conservation actions are retrofitting bathroom faucets and showerheads, but retrofitting toilets with HETs holds the greater potential of water savings. The rebates for high-efficiency laundry machines give EBMUD the highest water saving per unit cost of conservation. Other insights, such as the effectiveness of reduced landscape water requirement rebates (cash for grass) or price increase effects can also be produced by the model, and are presented in Cahill (2011).

The least-cost modeling approach, after further testing, has the potential to be applied to other neighborhoods or cities after adjusting the parameter distributions. The existing conditions model can be easily adapted to other communities or service areas using reasonable market penetration assumptions and adjusting for geographical factors. Both modeling components provide a more detailed and mechanistic understanding of household water use and conservation decisions based on physical parameters, rather than on empirical relationships like many traditional regression analysis approaches.
Acknowledgements. Special thanks belong to David Rosenberg for sharing his previously developed model for adaptation to the EBMUD neighborhood. Clifford Chan, Richard Harris, and David Wallenstein of EBMUD were willing to experiment and provided useful data and insights. Lisa Maddaus also provided helpful information about studies on residential use throughout California.

Edited by: S. Thompson

\section{References}

Anderson, E. T. and Song, I.: Coordinating price reductions and coupon events, J. Marketing Res., 41, 411-422, 2004.

Blokker, E. J. M., Vreeburg, J. H. G., and van Dijk, J. C.: Simulating Residential Water Demand with a Stochastic End-Use Model, J. Water Res. Pl.-ASCE, 136, 19-26, doi:10.1061/(Asce)Wr.19435452.0000002, 2010.

Cahill, R.: Household Water Use and Conservation Models Using Monte Carlo Techniques for the East Bay Municipal Utility District, Masters Tesis, Civil and Environmental Engineering, University of California, Davis, California, 92 pp., available at: http://cee.engr.ucdavis.edu/faculty/lund/ students/CahillMSThesis.pdf (last access: June 2013), 2011.

CALFED Bay Delta Program: Water Use Efficiency Comprehensive Evaluation, CALFED Bay Delta Program, Sacramento, California, available at: http://www.calwater.ca.gov/content/ Documents/library/WUE/2006_WUE_Public_Final.pdf (last access: October 2011), 2006.

CIMIS: Monthly Report Evapotransipration, Sacramento, California, available at: http://www.cimis.water.ca.gov (last access: October 2011), 2011.

Dalhuisen, J. M., Florax, R. J. G. M., de Groot, H. L. F., and Nijkamp, P.: Price and income elasticities of residential water demand: A meta-analysis, Land Econ., 79, 292-308, 2003.

DeOreo, W.: Analysis of Water Use in New Single-Family Homes, 155 pp., available at: http://www.aquacraft.com/node/64 (last access: October 2011), 2011.

DeOreo, W., Mayer, P. W., Martien, L., Hayden, M., Davis, D., Davis, R., Henderson, J., Raucher, R., Gleick, P., and Heberger, M.: Calfornia Single Family Water Use Efficiency Study, 387 pp., available at: http://www.aquacraft.com/ (last access: October 2011), 2011.

Dolinicar, S. and Hurlimann, A.: Australian's Water Conservation Behaviours and Attitudes, Australian Journal of Water Resources, 14, 43-53, 2010.

East Bay Municipal Utility District (EBMUD): Water Conservation Market Prenetration Study. Water Conservation Division, Water Resources Engineering, Inc., San Francisco, CA, available at: http://www.ebmud.com/sites/default/files/pdfs/market_ penetration_study_0.pdf (last access: October 2011), 2002.

East Bay Municipal Utility District (EBMUD): Water Rates and Service Charges, East Bay Municipal Utility District (EBMUD), available at: http://www.ebmud.com/for-customers/ account-information/water-rates-service-charges (last access: March 2011), 2010.

East Bay Municipal Utility District (EBMUD): Urban Water management Plan 2010, East Bay Municipal Utility District (EBMUD), Water Resources Planning Division, 
available at: http://www.ebmud.com/sites/default/files/pdfs/ UWMP-2010-2011-07-21-web-small.pdf (last access: March 2011), 2011.

Garcia-Alcubilla, R. and Lund, J. R.: Derived willingness-to-pay for household water use with price and probabilistic supply, J. Water Res. Pl.-ASCE, 132, 424-433, doi:10.1061/(Asce)07339496(2006)132:6(424), 2006.

Gleick, P., Haasz, D., Henges-Jeck, C., Srinivasan, V., Wolff, G., Cushing, K. K., and Mann, A.: Waste Not, Want Not: The Potential for Urban Water Conservation in California, Pacific Institute, available at: http://www.pacinst.org/wp-content/uploads/ 2013/02/waste_not_want_not_full_report3.pdf (last access: October 2013), 2003.

Gumbo, B., Juizo, D., and van der Zaag, P.: Information is a prerequisite for water demand management: experiences from four cities in Southern Africa, Phys. Chem. Earth, 28, 827-837, doi:10.1016/j.pce.2003.08.010, 2003.

Jacobs, H. E. and Haarhoff, J.: Structure and data requirements of an end-use model for residential water demand and return flow, Water Sa, 30, 293-304, 2004.

Kampragou, E., Lekkas, D. F., and Assimacopoulos, D.: Water demand management: implementation principles and indicative case studies, Water Environ. J., 25, 466-476, doi:10.1111/j.17476593.2010.00240.x, 2011.

Komor, P. S. and Wiggins, L. L.: Predicting Conservation Choice - Beyond the Cost-Minimization Assumption, Energy, 13, 633645,1988

Lund, J. R.: Derived Estimation of Willingness-to-Pay to Avoid Probabilistic Shortage, Water Resour. Res., 31, 1367-1372, 1995.

Mayer, P. W. and DeOreo, W.: Residential End Uses of Water, Denver, Colorado, available at: http://www.waterrf.org/ PublicReportLibrary/RFR90781_1999_241A.pdf (last access: October 2011), 1999.
Narasimhan, C.: A Price Discrimination Theory of Coupons, Journal of Marketing Science, 3, 128-147, 1984.

Rosenberg, D. E.: Residential Water Demand under Alternative Rate Structures: Simulation Approach, J. Water Resour. Pl.-ASCE, 136, 395-402, doi:10.1061/(Asce)Wr.19435452.0000046, 2010.

Rosenberg, D. E., Tarawneh, T., Abdel-Khaleq, R., and Lund, J. R.: Modeling integrated water user decisions in intermittent supply systems, Water Resour. Res., 43, W07425, doi:10.1029/2006wr005340, 2007.

Sacramento Department of Utilities: Urban Water Management Plan 2010, City of Sacramento, Sacramento, California, available at: http://www.cityofsacramento.org/ (last access: October 2011), 2011.

San Jose Environmental Services Department: 2010 Urban water management Plan, City of San Jose, San Jose California, available at: http://www3.sanjoseca.gov/ (last access: October 2011), 2011.

Sauri, D.: Lights and shadows of urban water demand management: The case of the metropolitan region of Barcelona, Eur. Plan. Stud., 11, 229-243, doi:10.1080/09654310303639, 2003.

Smirnov, N.: Tables for estimating the goodness of fit of empirical distributions, Ann. Math. Stat., 19, 279-281, 1948.

Sovocool, K.: Xeriscape Conversion Study, Southern Nevada Water Authority, available at: http://www.snwa.com/assets/pdf/about_ reports_xeriscape.pdf (last access: October 2011), 2005.

Wilchfort, G. and Lund, J. R.: Shortage management modeling for urban water supply systems, J. Water Resour. Pl.-ASCE, 123, 250-258, 1997.

Zillow: San Ramon Real Estate, available at: http:///www.zillow. com (last access: October 2011), 2011. 